\title{
POSTPARTUM PSYCHOSIS- A CLINICAL STUDY
}

\author{
Sunil Kumar Ahujaㅁ, Nimisha Mishra², Pradeep Kumar ${ }^{3}$
}

${ }^{1}$ Assistant Professor, Department of Psychiatry, S. S. Medical College, Rewa.

${ }^{2}$ Associate Professor, Department of Psychiatry, S. S. Medical College, Rewa.

3Professor, Department of Psychiatry, S. S. Medical College, Rewa.

\section{BACKGROUND}

ABSTRACT

Postpartum period is a very critical period in which many susceptible women develop various psychiatric disorders. These psychiatric disorders are grossly heterogeneous in nature, having diverse clinical manifestations and have different underlying aetiological factors.

Objective- The present study is carried out to study the various clinical variables associated with postpartum psychosis.

\section{MATERIALS AND METHODS}

The study was conducted on thirty postpartum psychosis patients admitted in female psychiatry ward. Detailed psychiatric evaluation including mental status examination along with obstetric \& menstrual profile was examined. Collected data were statistically analysed.

Study Design- This was an observational study at Inpatient Department of Psychiatry, S. S. Medical College and Associated SGMH, Rewa. The selected patients were subjected to detailed assessment and clinical diagnosis was made using ICD-10 criteria. Categorical data were analysed as numbers and percentage.

\section{RESULTS}

Maximum number of subjects were primipara (60\%). 73.33\% of subjects were in postpartum period of 4-8 days. Precipitating factors in physical area were present in as high as $40 \%$ subjects. $27 \%$ of subjects had history of fever and drug exposure prior to current episode of postpartum psychosis. Majority (70\%) of subjects underwent faith-healer and religious practices. Bipolar mood disorder was diagnosed in $33.33 \%$, acute depressive psychosis in $13.33 \%$, acute polymorphic psychosis in $26.66 \%$, drug-induced psychosis in $13.33 \%$, schizophrenia (type II) in $6.6 \%$ and paranoid psychosis in $6.6 \%$ patients. Most of subjects (83.33\%) were having average and stable personality. Acute polymorphic psychotic patients demonstrated complete recovery without residual deficit, none of these required longterm treatment. Subjects with drug-induced postpartum psychosis were taking chloroquine and ciprofloxacin.

\section{CONCLUSION}

The overall impression is that classical postpartum psychotic disorders have predominant signs and symptoms of affective disorder. Acute polymorphic psychosis appeared to be brittle in nature as our patients demonstrated complete recovery without any residual deficit. Acute psychosis should be promptly managed to avoid chronicity and harm to baby. Quick and correct diagnosis of type of postpartum psychosis is vital to expedite treatment, full recovery, prevention of further episodes and for healthy child rearing.

\section{KEYWORDS}

Postpartum Psychosis, Menstruation, Bipolar Mood Disorder, Schizophrenia.

HOW TO CITE THIS ARTICLE: Ahuja SK, Mishra N, Kumar P. Postpartum psychosis- A clinical study. J. Evolution Med. Dent. Sci. 2017;6(94):6815-6819, DOI: 10.14260/jemds/2017/1476

\section{BACKGROUND}

Good maternal health is warranted for healthy child development. Unfortunately, many susceptible women during postpartum period experience psychosis which usually is manifested after an asymptomatic period of 2 to 3 days and most often occurs during the first 3 weeks after delivery. ${ }^{1}$ Physiological changes (Hormonal, immunological, circadian etc) after birth precipitate psychosis in genetically vulnerable women. ${ }^{2}$

'Financial or Other Competing Interest': None.

Submission 20-11-2017, Peer Review 03-12-2017,

Acceptance 05-12-2017, Published 18-12-2017.

Corresponding Author:

Dr. Nimisha Mishra,

Associate Professor,

Department of Psychiatry, S. S. Medical College,

Rewa-486001, Madhya Pradesh.

E-mail: drnimishajss@gmail.com

DOI: $10.14260 /$ jemds $/ 2017 / 1476$
Postpartum psychosis is a severe form of mental disorder with incidence rate approximately $0.1 \% .3,4,5$ Hospitalisation is needed to ensure safety and management.2,5 Rapid management of mental disorders is essential for family functioning and parent-child relationship. ${ }^{6}$ About one third of women at risk develop postpartum relapse.,2,7

\section{MATERIALS AND METHODS Study Design}

The sample of present observational study consisted of 30 patients of postpartum psychosis, selected from the patients admitted in female psychiatry ward of Sanjay Gandhi Memorial Hospital, Rewa (MP) presenting with psychosis in postpartum period.

\section{Inclusion Criteria}

Women between 15 to 40 years of age, with full-term pregnancy or full-term caesarean section having first episode 
of postpartum psychosis with an onset within six weeks of delivery were included in this study.

\section{Exclusion Criteria}

Women with emergence of abnormal behaviour within three days of delivery, presence of overt neurological disorder e.g. meningitis, encephalitis; seizure disorder, etc. and presence of gross physical illness were excluded to remove elements of confounding.

The selected patients were subjected to detailed physical and clinical assessment with the help of semi-structured proforma. Detailed sociodemographic variables and psychosocial factors were recorded. A detailed menstrual and obstetric history was obtained including number of conception and number of deliveries conducted in past.

\section{Tools}

A psychiatric diagnosis was made after detailed psychiatric interview and mental status examination. ICD-10 criteria was used for diagnosis. Collected data were analysed in terms of number and percentage.

Each case was selected for routine investigation viz total WBC count and differential count and $\mathrm{HB} \%$, urine for routine and microscopy and blood sugar.

In some cases, further investigation such as peripheral smear for malarial parasite, blood Widal test, liver function test, blood grouping were also conducted wherever indicated.

\section{RESULTS}

In the abovementioned observational study, 30 diagnosed cases of postpartum psychosis following the inclusion criteria were enrolled in to the study.

Patient's clinical profile (parity, duration of illness in relation to postpartum psychosis, precipitating factors, family history of psychiatric disorder, menstrual history, premorbid personality, mental status examination) was observed.

Regarding parity the maximum number of subjects were primipara $(60 \%)$, para 2 were $26.67 \%$ and multipara were $13.33 \%$. In postpartum period, maximum number of cases were of postpartum period of 4-8 days $(73.33 \%)$. The other period during which large numbers of cases were seen was between 9 to 15 days (20\%). In $40 \%$ of subjects, precipitating factors were present and in rest (60\%) no precipitating factor could be detected. Fever and drugs were observed to be most important precipitating factor at $13.33 \%$ and $13.33 \%$ respectively. Among drugs, most common were Chloroquine and Ciprofloxacin. In $10 \%$ of patients, positive family history of psychiatric disorders in form of psychosis or other form were found and in the rest no genetic loading could be observed. $70 \%$ of patients underwent faith-healer practices before taking psychiatric treatment.

On assessment of the type of postpartum psychosis after history and mental status examination of 30 subjects, affective disorders were diagnosed in 10 patients (Mania-6, MDP depression-4), acute depressive psychosis in 4 subjects (Agitated depression-2, Retarded depression-2), acute polymorphic psychosis in 8 subjects, Drug-induced psychosis in 4 subjects, schizophrenia (type II) in 2 subjects and paranoid psychosis were found in 2 patients.

In relation to premorbid personality, 25 (83.33\%) subjects were having average and stable personality. Schizoid personality traits were seen in $16.67 \%$ subjects of MDP mania, and in 50\% subjects of Schizophrenia. Paranoid personality traits were observed in $50 \%$ patients of paranoid psychosis. Hysterical personality traits were seen in $12.5 \%$ cases of acute polymorphic psychosis whereas Cyclothymic personality trait were seen in $16.67 \%$ of Mania.

On physical examination, $30 \%$ patients were physically healthy at the time of hospitalisation. Anaemia was found in $40 \%$. Few subjects presented with fever (13.33\%), multiple abrasions \& bruises (16.67\%).

\begin{tabular}{|c|c|c|}
\hline \multirow{2}{*}{ Parity } & \multicolumn{2}{|c|}{ Patients $(n=30)$} \\
\hline & Number & Percentage \\
\hline Primipara & 18 & $60 \%$ \\
\hline II & 8 & $26.67 \%$ \\
\hline III or $>$ III & 4 & $13.33 \%$ \\
\hline \multicolumn{3}{|l|}{ Postpartum Period } \\
\hline 4-8 days & 22 & $73.33 \%$ \\
\hline 9-15 days & 6 & $20 \%$ \\
\hline$>16$ days & 2 & $6.67 \%$ \\
\hline \multicolumn{3}{|l|}{ Precipitating Factors } \\
\hline Absent & 18 & $60 \%$ \\
\hline Present & 12 & $40 \%$ \\
\hline Fever & 4 & $13.33 \%$ \\
\hline Drug & 4 & $13.33 \%$ \\
\hline Prolonged labour & 2 & $6.67 \%$ \\
\hline Postpartum haemorrhage & 2 & $6.67 \%$ \\
\hline \multicolumn{3}{|l|}{$\begin{array}{c}\text { Family History of } \\
\text { Psychiatric Disorder }\end{array}$} \\
\hline Present & 3 & $10 \%$ \\
\hline Absent & 27 & $90 \%$ \\
\hline \multicolumn{3}{|l|}{$\begin{array}{c}\text { Faith-healer/Religious } \\
\text { Practices } \\
\end{array}$} \\
\hline Present & 21 & $70 \%$ \\
\hline Absent & 09 & $30 \%$ \\
\hline \multicolumn{3}{|c|}{$\begin{array}{l}\text { Table 1. Clinical Profiles of Women Suffering } \\
\text { from Postpartum Psychosis }\end{array}$} \\
\hline
\end{tabular}

\begin{tabular}{|c|c|c|}
\hline Final Diagnosis & $\begin{array}{c}\text { Number of } \\
\text { Patients (n=30) }\end{array}$ & Percentage (\%) \\
\hline $\begin{array}{c}\text { Bipolar Mood } \\
\text { disorder } \\
\text { Mania } \\
\text { MDP depression }\end{array}$ & 6 & 33.33 \\
\hline $\begin{array}{c}\text { Acute depressive } \\
\text { psychosis } \\
\text { Agitated } \\
\text { Retarded }\end{array}$ & 2 & 13.33 \\
\hline $\begin{array}{c}\text { Acute polymorphic } \\
\text { psychosis }\end{array}$ & 2 & 26.66 \\
\hline $\begin{array}{c}\text { Drug-induced } \\
\text { psychosis }\end{array}$ & 4 & 13.33 \\
\hline $\begin{array}{c}\text { Schizophrenia } \\
\text { (Type II) }\end{array}$ & 2 & 6.6 \\
\hline Paranoid psychosis & 2 & 6.6 \\
\hline $\begin{array}{c}\text { Table 2. Postpartum Psychosis- Different Diagnostic } \\
\text { Categories (n=30) }\end{array}$ \\
\hline \multicolumn{2}{|c|}{} \\
\hline \multicolumn{2}{|c|}{} \\
\hline
\end{tabular}




\begin{tabular}{|c|c|c|c|c|c|}
\hline 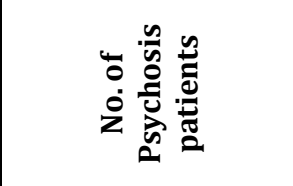 & 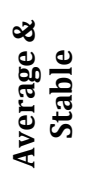 & 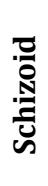 & م & 空 & 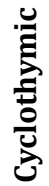 \\
\hline Mania(6) & 5 & 1 & & & 1 \\
\hline MDP depression (4) & 3 & & & & \\
\hline $\begin{array}{c}\text { Acute depressive } \\
\text { psychosis (4) }\end{array}$ & 4 & & & & \\
\hline $\begin{array}{c}\text { Acute polymorphic } \\
\text { psychosis (8) }\end{array}$ & 7 & & & 1 & \\
\hline $\begin{array}{l}\text { Drug-induced } \\
\text { psychosis (4) }\end{array}$ & 4 & & & & \\
\hline $\begin{array}{l}\text { Schizophrenia type II } \\
\text { (2) }\end{array}$ & 1 & 1 & & & \\
\hline $\begin{array}{c}\text { Paranoid psychosis } \\
(2)\end{array}$ & 1 & & 1 & & \\
\hline Total & 25 & 2 & 1 & 1 & 1 \\
\hline Table 3. Premor & 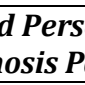 & & & & \\
\hline
\end{tabular}

\begin{tabular}{|c|c|c|}
\hline Physical Finding & No. of Cases (n=30) & Percentage \\
\hline Healthy & 9 & $30 \%$ \\
\hline Fever & 4 & $13.33 \%$ \\
\hline Anaemia & 12 & $40 \%$ \\
\hline Bruise & 5 & $16.67 \%$ \\
\hline $\begin{array}{c}\text { Table 4. Various Physical Findings among Patients } \\
\text { with Postpartum Psychosis (n=30) }\end{array}$ \\
\hline
\end{tabular}

\section{DISCUSSION}

The present study was devised to investigate various clinical variables of postpartum psychosis.

\section{Parity}

Majority of patients were primipara (60\%). Present study reveals that postpartum psychosis is more common in primipara and this finding also gets support from earlier studies. $8,9,10$

\section{Duration of Illness}

Most of the cases (93.33\%) presented within 15 days after delivery. This finding is supported by some studies, ${ }^{11}$ but not by others ${ }^{12}$ where in most of cases, illness occurred after two weeks.

\section{Precipitating Factors}

Forty percent patients developed psychosis in correlation with precipitating factors. The physical stress was mainly in the form of pyrexia $(13.33 \%)$, other important crucial precipitating factors were prolonged labour (6\%) and postpartum haemorrhage (6\%). Shehu et al (2015) have found physical comorbidities in around $77 \%$ of patients. 11 Some drugs like chloroquine and ciprofloxacin were also responsible for idiosyncratic manifestation of psychosis. $6.67 \%$ developed psychosis following chloroquine and ciprofloxacin administration respectively. It further reminds us for cautious use of these drugs, particularly in postpartum phase.

\section{Genetic Loading}

Genetic loading was present only in $10 \%$ cases. Our results thus emphasise the independent entity of postpartum psychiatric disorder and simply a phenotypic expression due to pre-existing genetic loading. The subtle role of genetic loading in induction of postpartum psychosis as observed in present study is well in conformity with early report by other studies. ${ }^{13,14}$

\section{Menstruation}

The large number of subjects $(60 \%)$ had regular menstruation; however, $40 \%$ subjects provided history of irregular menstruation. Increased incidence of irregular menstrual cycle observed in patients of postpartum psychosis may be a risk factor and postpartum psychosis could develop due to lack of rebound biochemical changes in pregnancy. ${ }^{15}$ One researcher concluded that oestradiol may have a causal relation to postpartum psychosis and significance in the treatment of this illness. ${ }^{16}$ Patients at high risk of puerperal manic-depressive illness develop a hypersensitivity of central D2 receptors which may be related to the effects of oestrogen withdrawal on the function of dopamine systems.17 Oestrogen has putative antipsychotic (dopaminergic) and antidepressant property. ${ }^{18}$

\section{Premorbid Personality Traits}

As such no specific premorbid personality could be identified in relation to postpartum psychosis. Certainly, the core psychosis like schizophrenic psychosis and MDP Mania were more in schizoid and cyclothymic personality respectively.

\section{Physical Examination}

Only $30 \%$ of the subjects were physically healthy, whereas majority $(70 \%)$ of the subjects revealed one or the other minor physical finding. Fever was present in $13 \%$ subjects and might be a precipitating factor; anaemia (40\%) was fairly higher and may point towards negligent attitude during antenatal phase. Bruise was present in $16 \%$ subjects as a result of violent behaviour and marked excitement. Higher comorbidity of Anaemia was also supported by other investigators. ${ }^{19}$

\section{Diagnostic Subcategories}

The observation of present study indicates that as high as seven clusters of clinical psychopathology could be subcategorised.

\section{Postpartum Psychiatric Disorder with Predominant Manic Symptoms (Mania n=6)}

As high as $20 \%$ subjects predominantly had clinical sign \& symptom similar to MDP Mania. This finding was similar to other investigators. ${ }^{20,21}$ Researchers reported postpartum psychosis belongs to bipolar mood disorder.22,23 How many of these patients are postpartum psychosis per se and how many are simply precipitated MDP Mania having few or more future episodes of either mania or depression unrelated to pregnancy could only be answered on longterm follow-up. Absence of past and family history of MDP goes certainly in favour of aetiopathological role of postpartum in genesis of this disorder. Various investigators 24,13 have postulated psychological factor and other 15,16 hormonal factors in aetiopathogenesis of postpartum psychiatric disorders. Reich and Winokur (1970) stated that manic patients have high puerperal breakdown rates. ${ }^{25}$ 


\section{MDP Depression ( $n=4)$}

Four patients were diagnosed as MDP depression. In two patients family history of MDP and in other two patients past history of brief hypomanic phase was present. All these subjects were having psychomotor retardation, poor concentration, depressed affect and retarded flow of speech. Allan Seltzer reported of physical and mental lethargy, sadness and self-accusation, feelings of futility and unworthiness in severely depressed unipolar or bipolar patient. Morbid delusions of the patient having diseased or deformed genitals, or infecting the child with venereal disease, of having been unfaithful, or of the baby being dead or deformed, are also seen. ${ }^{26}$

2. Acute Depressive Psychosis $(n=4)$

Four subjects had major depression, of these two patients had retarded and two patients had agitated picture. Along with Sadness and self-accusations of unworthiness, suicide or infanticide also observed with hopelessness, complete dejection and subjective feeling of depression. David et al (1942) observed physical and mental lethargy, retardation of thought and action. ${ }^{27}$ In psychotic depression, excessive concern with the baby's health, guilt about lack of love, and delusions about the infant being dead or defective are common. She may deny having given birth or report hallucinations that command her to harm the baby. ${ }^{1}$ One researcher observed that postpartum depressive patients differed significantly from non-puerperal controls in being more deluded or hallucinated, more labile and more disoriented.28 The children of postpartum depressed mothers may have negative child developmental outcomes ${ }^{29}$ suggesting that postpartum depression may have a longterm negative impact on the family.

3. Acute Polymorphic Psychosis (n=8)

In eight patients of acute polymorphic psychosis, four patients had febrile psychosis, two had prolonged labour and another two had postpartum haemorrhage. In four patients of febrile psychosis, two patients had deteriorated appearance and manner and other two patients had gross bizarre behaviour, emotional turmoil and thought process disturbance. Disturbance in thought content could not be elicited. Gross bizarre behaviours were also observed in patients of prolonged labour (two cases) and postpartum haemorrhage (two cases). Two patients of prolonged labour also had disturbance in thought content, occasional guilt, ill-sustained grandiose ideas alternating with hopelessness, worthlessness and helplessness. Affect was shallow and perplexed in patients of prolonged labour. No perceptual disturbances were found. All aforesaid florid productive symptoms were highly volatile and variable throughout acute illness. All these patients demonstrated complete recovery without any residual deficit and their psychosis appeared brittle in nature. None of these patients needed longterm treatment.

4. Drug-induced psychosis $(n=4)$

Two subjects who were undergoing antimalarial treatment (chloroquine) developed acute psychotic presentation. Hydrochloroquine induced neuropsychiatric symptoms present as delirium, hallucinations, maniac episodes or depression after an interval of a few hours to 40 days, usually regress one week after suspension of the synthetic antimalarial. ${ }^{30}$ Chloroquine can cause insomnia, toxic confusional psychosis, personality changes, mania and suicidal impulses. ${ }^{31}$ Psychotic symptoms get resolved within 14 days following recovery from fever and drug withdrawal with the advent of active antipsychotic treatment. Druginduced psychosis seems to be brittle and did not require longterm treatment.

\section{Schizophrenia $(n=2)$}

The clinical presentation of postpartum psychosis similar to schizophrenic psychosis was significantly lower in the present study, which also gets support from other investigators J. Davidson et al reported significantly lesser schizophrenic signs and symptoms in postpartum psychosis. ${ }^{32}$ The schizophrenic patient shows thought disorder, delusions, inappropriate affect and hallucinations. The patient may exhibit motor agitation or retardation (catatonic features). She may express bizarre ideas about herself or the infant and, like the manic patient, is usually unaware of her problem. ${ }^{1}$

6. Paranoid Psychosis $(n=2)$

Two patients were diagnosed as paranoid schizophrenic psychosis. They had deteriorated appearance and manner, while one had shallow affect, the other had depressed affect. There was no disturbance of thought process. They revealed frank persecutory delusion and diverse nature. One patient also had auditory hallucination in form of voice commenting. One investigator also reported the precipitation of paranoid disorder in postpartum phase. ${ }^{32}$ It is difficult to comment whether pregnancy has simply precipitated paranoid schizophrenia in vulnerable subjects or some biological process in postpartum phase had triggered paranoid process.

\section{CONCLUSION}

1. Primipara is most vulnerable group for developing postpartum psychosis.

2. Classic postpartum psychiatric disorders have predominance of signs and symptoms pertaining to mood disorder.

3. Depressive state should be recognised as early as possible to prevent negative impact on child development.

4. Our study suggests patients presenting with acute polymorphic psychosis in postpartum phase have one or other precipitating event; hence complete examination and investigation of these patients is warranted to find out any precipitating event so that holistic care can be instituted.

5. Acute polymorphic psychosis in postpartum stage is of brittle nature as it requires short term treatment, complete recovery without any residual deficit.

6. Identification of schizophrenic categories from other benign postpartum psychotic disorder is mandatory to have successful acute as well longterm clinical management.

7. Postpartum psychosis still poses a clinical dilemma due to varied manifestations. The inclusion of all kinds of psychosis in temporal correlation with postpartum phase within a period of 6 weeks makes this group markedly heterogeneous. Still postpartum psychosis as 
an independent disorder needs proper clinical guidelines and specific sign and symptoms.

8. Well-designed biochemical studies are imperative to establish linkage between hormonal balance following postpartum phase and emerging psychotic disorder.

9. Quick and correct diagnosis of type of postpartum psychosis is vital to expedite treatment and for full recovery, prevention of further episodes and shrink the risk to mother, baby and her family.

10. Early identification and a prompt management should be delivered by gynaecologist too by promoting awareness about this disorder and allaying confusion with other organic delirious condition. Integrated and holistic approach of a psychiatrist, gynaecologist and physician is necessary for achieving and caring global health of all females, particularly in postpartum phase.

\section{REFERENCES}

[1] Robinson GE, Stewart DE. Postpartum psychiatric disorders. Can Med Assoc J 1986;134(1):31-7.

[2] Bergink V, Rasgon N, Wisner KL. Postpartum psychosis: madness, mania \& melancholia in motherhood. Am J Psychiatry 2016;173(12):1179-88.

[3] Munk-Olsen T, Laursen TM, Pedersen CB, et al. New parents and mental disorders: a population-based register study. JAMA 2006;296(21):2582-9.

[4] Gale S, Harlow BL. Postpartum mood disorders: a review of clinical and epidemiological factors. J Psychosom Obstet Gynaecol 2003;24(4):257-66.

[5] Wesseloo R, Burgerhout KM, Koorengevel KM, et al. Postpartum psychosis in clinical practice: diagnostic considerations, treatment and prevention. Tijdschr Psychiatr 2015;57(1):25-33.

[6] Bydlowski S. Postpartum psychological disorders: screening and prevention after birth. Guidelines for clinical practice. J Gynecol Obstet Biol Report (Paris) 2015;44(10):1152-6.

[7] Wesseloo R, Kamperman AM, Munk-Oslen T, et al. Risk of postpartum relapse in bipolar and postpartum psychosis: a systematic review and meta-analysis. Am J Psychiatry 2016;173(2):117-27.

[8] Shrestha N, Hazrah P, Sagar R. Incidence and prevalence of postpartum depression in a rural community of India. Journal of Chitwan Medical College 2015;5(2):11-9.

[9] Di Florio A, Jones L, Forty L, et al. Mood disorders and parity-a clue to the aetiology of the postpartum trigger. J Affect Disord 2014;152-154:334-9.

[10] Thomas CL, Gordon JE. Psychosis after childbirth: ecological aspects of a single impact stress. Am J Med Sci 1959;238:363-88.

[11] Shehu CE, Yunusa MA. Obstetric characteristics and management of patient with postpartum psychosis in a tertiary hospital setting. Obstet Gynecol Int Article ID 386409, 2015;2015:5.

[12] Adewunmi AB, Gureje O. Puerperal psychiatric disorders in Nigerian women. East Afr Med J 1991;68(10):775-81.
[13] Protheroe C. Puerperal psychosis: a long term study 1927-61. Br J Psych 1969;115(518):9-30.

[14] Makanjuola RO. Psychotic disorders after childbirth in Nigerian women. Trop Geogr Med 1982;34(1):67-72.

[15] Treadway CR, Kane FJ, Jarrahi-Zadeh A, et al. A psychoendocrine study of pregnancy and puerperium. Am J Psychiatry 1969;125(10):1380-6.

[16] Ahokas A, Aito M. Role of estradiol in puerperal psychosis. Psychopharmacology (Berl) 1999;147(1):108-10.

[17] Wieck A. Endocrine aspects of postnatal mental disorder. Baillieres Clin Obstet Gynaecol 1989;3(4):857-77.

[18] Cutter WJ, Norbury R, Murphy DG. Oestrogen, brain function, and neuropsychiatric disorders. JNNP 2003;74(7):837-40.

[19] Ndosi NK, Mtawali ML. The nature of puerperal psychosis at Muhimbili national hospital: its physical co-morbidity associated main obstetric and social factors. Afr J Reprod Health 2002;6(1):41-9.

[20] Okano T, Nomura J, Kumar R, et al. An epidemiological and clinical investigation of postpartum psychiatric illness in Japanese mothers. J Affect Disord 1998;48(23):233-40.

[21] Brockington IF, Cernik KF, Schofield EM, et al. Puerperal psychosis. Phenomena and diagnosis. Arch Gen Psychiatry 1981;38(7):829-33.

[22] Gressier F, Letranchant A, Hardy P. Post-partum psychosis. Rev Prat 2015;65(2):232-4.

[23] Kendell RE, Chalmers JC, Platz C. Epidemiology of puerperal psychosis. Br J Psychiatry 1987;150:662-73.

[24] Hemphill RE. Incidence and nature of puerperal psychiatric illness. Br M J 1952;2(4796):1232-5.

[25] Reich T, Winokur G. Postpartum psychosis in patients with manic depressive disease. J Nerv Ment Dis 1970;151(1):60-8.

[26] Seltzer A. Postpartum mental syndromes. Can Fam Physician 1980;26:1546-50.

[27] Boyd DA. Mental disorder associated with childbearing. Am J Obst and Gyne 1942;43(2):335-49.

[28] Dean C, Kendell RE. The symptomatology of puerperal illnesses. Br J Psychiatry 1981;139:128-33.

[29] Parsons CE, Young KS, Rochat TJ, et al. Postnatal depression and its effects on child development: a review of evidence from low and middle income countries. Br Med Bull 2012;101:57-9.

[30] Ferravo V, Mantoux F, Denis K, et al. Hallucination during treatment with hydrochloroquine. Ann Dermatol Venerol 2004;131(5):471-3.

[31] Akhtar S, Mukherjee S. Chloroquine induced mania. Int J Psychiatry Med 1993;23(4):349-56.

[32] Davidson J, Robertson E. A follow-up study of post of partum illness, 1946-1978. Acta Psychiatr Scand 1985;71(5):451-7. 